\title{
The proinflammatory mediator macrophage migration inhibitory factor induces glucose catabolism in muscle
}

\author{
Fabio Benigni, ${ }^{1}$ Toshiya Atsumi, ${ }^{1}$ Thierry Calandra,,${ }^{1,2}$ \\ Christine Metz, ${ }^{1}$ Bernd Echtenacher, ${ }^{3}$ Tina Peng, ${ }^{1}$ and Richard Bucala ${ }^{1}$ \\ ${ }^{1}$ The Picower Institute for Medical Research, Manhasset, New York, USA \\ ${ }^{2}$ Division of Infectious Diseases, Centre Hospitalier Universitaire Vaudois, Lausanne, Switzerland \\ ${ }^{3}$ Department of Pathology, Tumor Immunology, University of Regensburg, Regensburg, Germany
}

Address correspondence to: Richard Bucala, The Picower Institute for Medical Research, 350 Community Drive, Manhasset, New York 11030, USA. Phone: (516) 562-9406; Fax: (516) 869-6097; E-mail: rbucala@ picower.edu.

Received for publication March 17, 2000, and accepted in revised form October 17, 2000.

\begin{abstract}
Severe infection or tissue invasion can provoke a catabolic response, leading to severe metabolic derangement, cachexia, and even death. Macrophage migration inhibitory factor (MIF) is an important regulator of the host response to infection. Released by various immune cells and by the anterior pituitary gland, MIF plays a critical role in the systemic inflammatory response by counterregulating the inhibitory effect of glucocorticoids on immune-cell activation and proinflammatory cytokine production. We describe herein an unexpected role for MIF in the regulation of glycolysis. The addition of MIF to differentiated L6 rat myotubes increased synthesis of fructose 2,6-bisphosphate (F2,6BP), a positive allosteric regulator of glycolysis. Increased expression of the enzyme 6-phosphofructo-2-kinase/fructose-2,6-bisphosphatase (PFK-2) enhanced F2,6BP production and, consequently, cellular lactate production. The catabolic effect of TNF- $\alpha$ on myotubes was mediated by MIF, which served as an autocrine stimulus for $\mathrm{F} 2,6 \mathrm{BP}$ production. TNF- $\alpha$ administered to mice decreased serum glucose levels and increased muscle F2,6BP levels; pretreatment with a neutralizing anti-MIF $\mathrm{mAb}$ completely inhibited these effects. Anti-MIF also prevented hypoglycemia and increased muscle F2,6BP levels in TNF- $\alpha$-knockout mice that were administered LPS, supporting the intrinsic contribution of MIF to these inflammation-induced metabolic changes. Taken together with the recent finding that MIF is a positive, autocrine stimulator of insulin release, these data suggest an important role for MIF in the control of host glucose disposal and carbohydrate metabolism.
\end{abstract}

J. Clin. Invest. 106:1291-1300 (2000).

\section{Introduction}

Severe injury, infection, or tissue invasion is often accompanied by a hypermetabolic response that can lead to significant derangements in host carbohydrate, lipid, and protein metabolism. An increase in tissue lactate production together with a transient hyperglycemia and a relative state of insulin resistance occur early in the course of this response. This is followed by the depletion of hepatic glycogen stores and a persistent hypoglycemic condition. Over time, a refractory catabolic state develops and evolves into a dominant feature of the host response. If unresolved, this can lead to excessive tissue wasting, cachexia, and even death (1).

The evolution of this catabolic state has been linked both to a derangement of normal hormonal responses and to the sustained expression of immune cell-derived, proinflammatory mediators. Among the cytokines that circulate in high levels during severe inflammation, TNF- $\alpha$ has been noted to exert important catabolic effects (1). In peripheral muscle, which is the predominant site of glucose disposal in the body, TNF- $\alpha$ induces the synthesis of the powerful, positive allosteric stimulator of glycolysis, fructose 2,6-bisphosphate (F2,6BP), leading to a depletion of intracellular glycogen and the increased production of lactic acid (2). Tissue perfusion studies, however, have suggested that TNF- $\alpha$ does not exert a direct effect on muscle glucose metabolism, but rather that it may act via the induction of additional, downstream mediators $(3,4)$. TNF- $\alpha$ also may contribute to the development of insulin resistance that can occur as a consequence of a systemic inflammatory response, and an emerging body of data has implicated tissue TNF- $\alpha$ expression in the insulin resistance of diabetes mellitus and obesity $(1,5,6)$.

The protein known as macrophage migration inhibitory factor (MIF) has emerged as an important regulator of inflammation $(7,8)$, playing a central role in the control of both innate and antigen-specific immunity (9-14). Although first described as a $\mathrm{T}$ cell-derived activity, MIF has been shown recently to be released by a variety of cell types. Within the immune system, monocytes/macrophages, T lymphocytes, and eosinophils are a major source of the MIF that is released after exposure to microbial toxins, antigens, or cytokines (11-16). MIF activates $\mathrm{T}$ cells, is required for antibody production by $\mathrm{B}$ cells, and has the unique ability to counterregulate the inhibitory effects of glucocorticoids on cytokine production and immune cell 
activation $(12,17)$. MIF also has been shown to be released by several endocrine cell types. The anterior pituitary gland secretes MIF as part of the systemic response to stress and infection $(10,17,18)$, and a recent study has shown MIF to be colocalized with insulin in the $\beta$-cells of the pancreatic islets, where it acts to regulate the release of insulin (19).

Given the widespread pattern of MIF expression and action under both physiological and pathological conditions, we sought to explore the potential role of MIF in host metabolic responses. We have investigated the effect of rMIF and anti-MIF on glycolysis in vitro and in vivo. Our data implicate MIF in the control of peripheral glucose metabolism and in mediating certain of the catabolic effects induced by severe inflammatory responses.

\section{Methods}

Materials. Reagent grade chemicals were obtained from Sigma Chemical Co. (St. Louis, Missouri, USA). 2Deoxy- $\left[{ }^{3} \mathrm{H}\right]$ glucose was procured from NEN Life Science Products Inc. (Boston, Massachusetts, USA). Murine recombinant $\left(10^{7} \mathrm{U} / \mathrm{g}\right.$ protein $)$ was obtained from R\&D Systems (Minneapolis, Minnesota, USA), and human TNF- $\alpha\left(10^{6} \mathrm{U} / \mathrm{g}\right.$ protein $)$ was prepared from an Escherichia coli expression system. Recombinant mouse MIF was expressed, purified, and reconstituted as described previously (20). Mouse MIF differs from rat MIF by only a single, nonbiologically significant amino acid substitution $(20,21)$. Pure recombinant MIF contained less than $10 \mathrm{pg}$ of endotoxin per microgram recombinant protein as determined by the chromogenic Limulus amoebocyte assay (LAL-Test; BioWhittaker Inc., Walkersville, Maryland, USA). Mouse monoclonal

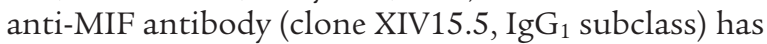
been described previously, neutralizes mouse or rat MIF bioactivity in vitro and in vivo $(12-14,22,23)$ and contained less than $4 \mathrm{pg}$ of endotoxin per microgram immunoglobulin as prepared for these studies.

Cell culture. L6 rat myoblasts were obtained from American Type Culture Collection (CRL-1458; Rockville, Maryland, USA). These cells were plated at an initial density of $2 \times 10^{5} / \mathrm{ml}$ and maintained in DMEM $/ 10 \%$ FBS at $37^{\circ} \mathrm{C}$ in a $5 \% \mathrm{CO}_{2}$ atmosphere. Differentiation into myotubes was induced by treatment with bovine insulin $(0.3 \mu \mathrm{M}$; Life Technologies Inc., Grand Island, New York, USA) in DMEM $/ 1 \%$ horse serum. After 3 days of incubation, the cells were washed once and the medium replaced. Stimulations with rat TNF- $\alpha$ (R\&D Systems) or MIF were performed for 24-72 hours.

$\mathrm{H}$-4-II-E rat hepatoma cells (ATCC) were cultured in MEM with nonessential amino acids and Earle's BSS (Life Technologies Inc.) containing 10\% heat-inactivated FBS and $10 \%$ calf serum (CS) (HyClone Laboratories, Logan, Utah, USA) at $37^{\circ} \mathrm{C}$ in a humidified atmosphere with $5 \% \mathrm{CO}_{2}$.

F2, 6BP assay. Fully differentiated L6 cells were preincubated with anti-MIF mAb or isotype control antibodies $(10-100 \mu \mathrm{g} / \mathrm{ml})$ for 2 hours. Cells then were stimulated with $10-100 \mathrm{ng} / \mathrm{ml}$ TNF- $\alpha$ or medium alone for an additional 24-72 hours. At indicated times, the cells were washed with serum-free medium and disrupted by adding $0.8 \mathrm{ml}$ of $50 \mathrm{mM} \mathrm{NaOH}$. F,2,6BP was extracted and measured according to Van Schaftingen's method (24).

Glucose transport assay. Glucose uptake into cells was measured following an established protocol (25). Briefly, differentiated $\mathrm{L} 6$ cells were pretreated with either antiMIF mAb or control isotype (IgG1) and then incubated for 24 hours with or without rat TNF- $\alpha(10 \mathrm{ng} / \mathrm{ml})$. This was followed by the addition of insulin $(0.6 \mu \mathrm{M})$ or medium alone for 45 minutes. Cells were washed twice with transport solution (140 mM NaCl, $20 \mathrm{mM}$ HEPES/Na, $5 \mathrm{mM} \mathrm{KCl}^{2} .5 \mathrm{mM} \mathrm{MgSO}_{4}$, and $1 \mathrm{mM} \mathrm{CaCl}_{2}$ ), and incubated for 10 minutes with $10 \mathrm{mM}$ 2-deoxyglucose containing $0.3 \mu \mathrm{Ci} / \mathrm{ml}$ of 2 -deoxy- $\left[{ }^{3} \mathrm{H}\right]$ glucose. After a 10 minute incubation, the cells were washed three times with transport solution and lysed with $1 \mathrm{ml}$ of $50 \mathrm{mM}$ $\mathrm{NaOH}$. The lysates then were collected, and the radioactivity was measured by scintillation counting. Total protein content was measured by using Bio-Rad Reagent (Bio-Rad Laboratories Inc., Richmond, California, USA). Cytocalasin B $(10 \mu \mathrm{M})$ was used to determine non-carrier-mediated deoxyglucose uptake.

Phosphoenolpyruvate carboxykinase activity. Rat hepatoma H-4-II-E cells were plated at $2 \times 10^{6}$ cells per well in $3.5-\mathrm{cm}$ tissue culture plates (Flow, McLean, Virginia, USA). After 6 hours, the nonadherent cells were removed and then incubated overnight in serum-free medium. The next day, the cells were incubated with MIF $(0.1-10 \mathrm{ng} / \mathrm{ml})$ or dexamethasone $\left(10^{-8} \mathrm{M}\right)$ given either alone or in combination. After 6 hours of stimulation, the cells were harvested by gentle scraping and homogenized in $1 \mathrm{ml}$ of $0.25 \mathrm{M}$ sucrose, $10 \mathrm{mM}$ Tris$\mathrm{HCl}(\mathrm{pH} 7.01)$ buffer with a teflon homogenizer (26,000 rpm for 15 seconds). Cell cytosol preparations were obtained after centrifugation and phosphoenolpyruvate carboxykinase (PEPCK) activity was measured by the ${ }^{14} \mathrm{C}$ radiometric method of Chang and Lane (26) as described previously (27). Results were expressed as counts per minute per microgram of cytosol protein. Protein concentration in cytosol preparations was determined using the Bio-Rad protein assay kit (Bio-Rad Laboratories Inc.), and a standard curve prepared with BSA (Sigma Chemical Co.).

Miscellaneous liver and plasma assays. Liver glycogen content was measured as described previously (28). Briefly, aliquots of liver tissue (flash frozen and preserved in liquid $\mathrm{N}_{2}$ ) were homogenized at high speed together with five parts by weight of ice-cold perchloric acid (10\%). Aliquots $(200 \mu \mathrm{l})$ were removed for measurement of glycogen hydrolysis into glucose, using the aminoglucosidase method (28). Blood lactate, glucose, and total triglyceride determinations were performed by using commercially available kits obtained from Sigma Chemical Co. Serum insulin levels were measured by RIA following the manufacturer's protocol (Linco Research, St. Louis, Missouri, USA). 
$m R N A$ expression analyses. Total RNA was extracted from differentiated $\mathrm{L} 6$ cells with an RNAzol B solution (Tel-Test Inc., Friendswood, Texas, USA). The following rat cDNA primers were designed and custom synthesized: GAPDH (360 bp), 5'-ACCCCCAATGTATCCGTTGT3', 5'-CCCTGTTGCTGTAGCCATAT-3'; MIF (430 bp), 5'-CCTATGTTGATCGTGAACAC-3', 5'-AGTTGATGTAGACCCGGTC-3'); and rat muscle isoform PFK2 (780 bp), 5' CAGTATGCAGAGGACACTTG-3'， 5'-CACACCTCGATCTATCTACC-3' $(15,21)$. cDNA was reverse-transcribed from $3 \mu \mathrm{g}$ of RNA in $0.1 \mathrm{ml}$ reaction mixtures containing $400 \mathrm{U}$ of MMLV RT and $0.25 \mathrm{ng}$ of oligo-(dT) (Life Technologies Inc.). Aliquots $(3 \mu \mathrm{l})$ of cDNA then were amplified by PCR in a Perkin-Elmer model 9600 thermal cycler (Perkin-Elmer, Norwalk, Connecticut, USA) using the primers listed and the following cycling program: denaturation for 30 seconds at $95^{\circ} \mathrm{C}$, annealing for 30 seconds at $53^{\circ} \mathrm{C}$, and extension for 30 seconds at $72^{\circ} \mathrm{C}$ for 27 cycles with a final extension for 7 minutes at $72^{\circ} \mathrm{C}$. Preliminary PCR and densitometric analyses of gel electrophoresis products were carried out to ensure that the reaction conditions fell within a linear range for cDNA amplification.

ELISA and Western blot analysis for MIF. Supernatants and lysates from L6 cells were diluted 1:5 and assayed by sandwich ELISA for MIF following a previously reported procedure (11). Western blotting analysis was used for the analysis of MIF content in mouse plasma because the presence of anti-MIF $\mathrm{mAb}$ in the blood of treated mice interfered significantly with the sandwich ELISA. Briefly, $10 \mu \mathrm{l}$ aliquots of mouse plasma were pooled ( $n=5$ mice per experimental group), diluted 1:2 with $\mathrm{ddH}_{2} \mathrm{O}$, and mixed with an equal volume of $2 \mathrm{x}$ Laemmli loading buffer. The samples were boiled for 5 minutes, and the proteins were separated by electrophoreses in polyacrylamide-SDS gels (4-20\% gradient). After transfer to Immobilon-P membranes (Millipore Corp., Bedford, Massachusetts, USA), the proteins were incubated with a polyclonal anti-MIF antibody $(1: 1,000)$. Bound antibody was visualized with horseradish peroxidase-conjugated goat anti-rabbit antibody and chemiluminescence using the ECL system (Amersham, Buckinghamshire, United Kingdom). Single immunoreactive bands corresponding to MIF were observed and quantified by laser densitometry with reference to simultaneously electrophoresed rMIF standards (1-20 ng). That this method could discriminate between baseline and elevated plasma MIF levels was verified by spiking experiments in which recombinant MIF was added to mouse blood before Western blotting analysis.

Animal studies. Mice were housed in groups of five to ten per cage and had free access to food (Purina mouse chow; Ralston-Purina, St. Louis, Missouri, USA) and water. After a 5-day acclimitization period, all experiments commenced at the same time of day. Control mice (18-20 g, male; $n=5$ animals per experimental group) were injected intraperitoneally with 100 $\mu \mathrm{g} /$ mouse of either anti-MIF mAb (clone XIV15.5) or control isotype antibody $\left(\operatorname{IgG}_{1}\right) 2$ hours before the administration of recombinant TNF- $\alpha(160 \mu \mathrm{g} / \mathrm{kg}$, intravenously). The TNF- $\alpha^{-/-}$(TNF- $\left.\alpha-\mathrm{KO}\right)$ or control mice were injected intraperitoneally with $16.6 \mathrm{mg}$ LPS (E. coli 0111:B4) per kilogram mouse. At the indicated times, blood was collected from the retro-orbital sinus under light anesthesia, and the mice were sacrificed by $\mathrm{CO}_{2}$ asphyxiation. Liver and muscle were collected and immediately frozen in liquid $\mathrm{N}_{2}$ before tissue analyses.

\section{Results}

MIF induces F2,6BP and lactate production in muscle myotubes. F2,6BP is the most powerful allosteric activator of the glycolytic pathway, and intracellular F2,6BP concentrations provide a useful measure of the rate of glycolytic flux in cells (29). F2,6BP stimulates phosphofructokinase-1 activity by increasing its affinity for fructose-6-phosphate and by diminishing the negative allosteric effect of ATP (2). In agreement with previous work (30), we found that TNF- $\alpha$ stimulates the production of F2,6BP in differentiated L6 muscle myotubes (Figure 1a; also see Figure 3a). Exogenously added recombinant mouse MIF in a dose range of $5-100 \mathrm{ng} / \mathrm{ml}$ also increased F2,6BP levels in L6 muscle myotubes. High intracellular F2,6BP concentrations were detectable at 24 hours after treatment with MIF, and stimulation with TNF- $\alpha$ together with MIF did not produce any additive effect when compared with stimulation by either mediator alone (data not shown). L6 cell production of F2,6BP was found to be insensitive to endotoxin $(\leq 10 \mu \mathrm{g} / \mathrm{ml})$, negating the remote possibility that trace endotoxin contamination may have contributed to the stimulatory effects observed with MIF or TNF- $\alpha$.

F2,6BP is the product of the bifunctional enzyme, 6phosphofructo-2-kinase/fructose-2,6-bisphosphatase (PFK-2), which is expressed in several tissue-specific isoforms (2). Proinflammatory stimulation of human monocytes, for instance, has been shown to increase the mRNA levels of a unique PFK-2 isoform that bears cytokine-like, AU-rich regulatory elements in its $3^{\prime}$ untranslated region (31). We examined whether the TNF- $\alpha$ - or MIF-mediated increase in F2,6BP levels also was associated with an increase in the expression of the PFK-2 gene. As shown in Figure 1b, both MIF and TNF- $\alpha$ treatment stimulated an increase in PFK-2 mRNA levels in rat muscle cells. Whether these PFK-2 transcripts represent the murine homolog of this AUrich PFK is unknown and must await the molecular cloning of this isoform from rat.

The metabolic end product of glycolysis is pyruvate, which may be further consumed by the tricarboxylic acid cycle to produce $\mathrm{CO}_{2}$ and $\mathrm{H}_{2} \mathrm{O}$ or may be reduced to lactate and released from cells. Enhanced lactate production accompanies TNF- $\alpha$ treatment of many cell and tissue types $(32,33)$, and we found that like TNF- $\alpha$, MIF stimulation increased lactate release from L6 myotubes (Figure 1c). Cotreatment of muscle cells with TNF- $\alpha$ and MIF across a range of concentrations also did not result in any 
further increase in lactate secretion when compared with stimulation by either mediator alone (data not shown).

TNF- $\alpha$ induces MIF secretion from L6 muscle cells. MIF exists preformed in several cell types, and prior studies have shown that endogenously-released MIF can stimulate macrophage, $\mathrm{T}$-cell, and fibroblast activation responses in an autocrine fashion $(11,12,23)$. TNF- $\alpha$

a

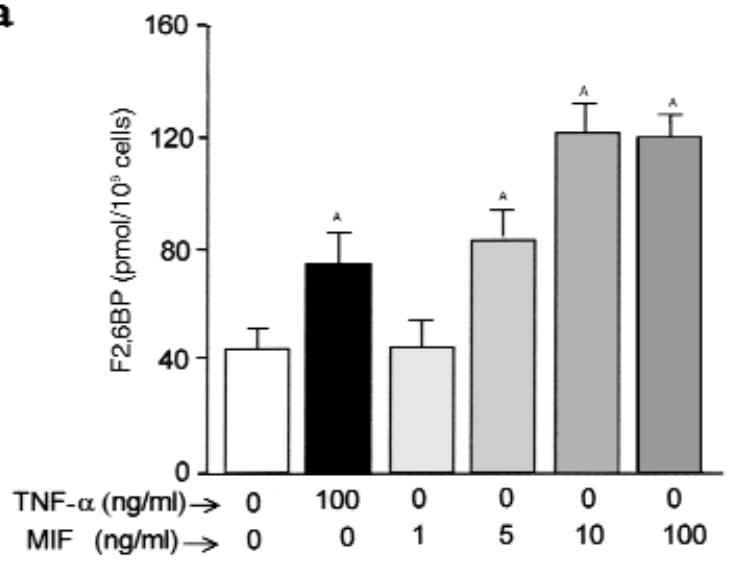

b

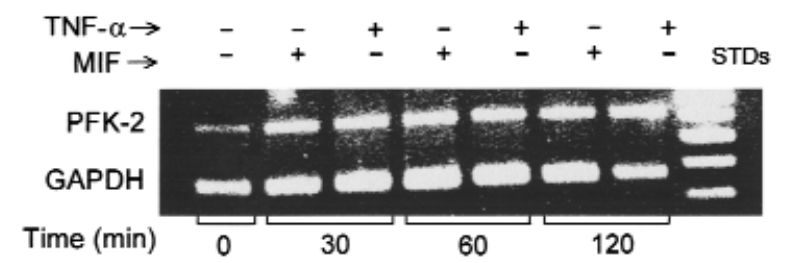

c

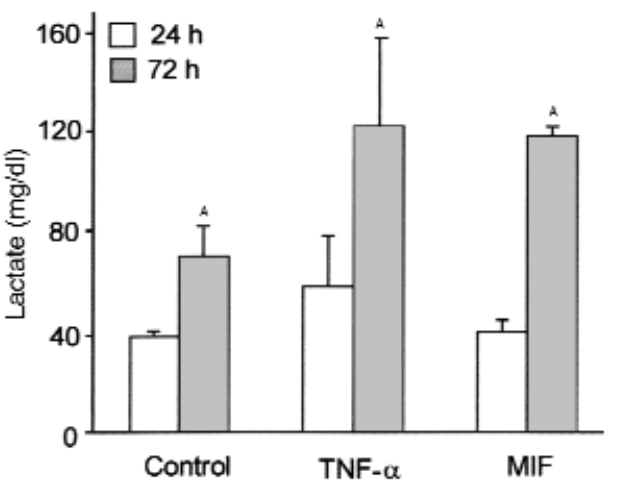

Figure 1

(a) Intracellular F2,6BP levels in L6 myotubes. Fully differentiated L6 muscle cells were stimulated with TNF- $\alpha(100 \mathrm{ng} / \mathrm{ml})$ or MIF (1-100 $\mathrm{ng} / \mathrm{ml}$ ) for 72 hours at $37^{\circ} \mathrm{C}$. Lysates were prepared and analyzed for F2,6BP content as described in Methods. Data are expressed as mean $\pm \mathrm{SD}\left({ }^{A} P<0.05\right.$ versus control medium) of triplicate wells and are representative of three independently performed experiments. (b) Induction of rat muscle PFK- 2 expression by TNF- $\alpha$ or MIF in L6 muscle cells, as detected by RT-PCR analysis using gene-specific primers. The amplification cycle number was varied initially in order to establish a linear amplification response, as assessed by laser densitometric analysis. (c) Lactate production by L6 myotubes. Differentiated L6 muscle cells ( 1.4 $\times 10^{6}$ cells per well) were stimulated with either TNF- $\alpha$ or MIF (each at $100 \mathrm{ng} / \mathrm{ml}$ ). Supernatants were collected at 24 and 72 hours after stimulation, and the lactate levels were measured. Data are expressed as mean $\pm \mathrm{SD}\left({ }^{A} P<0.05\right.$ versus control medium) of triplicate wells and are representative of three independently performed experiments. also has been shown to induce MIF release from macrophages (11), and we considered therefore that the TNF- $\alpha$-mediated effect on PFK-2 expression and glycolytic flux in L6 myotubes might result from the release of endogenous MIF protein by TNF- $\alpha$ stimulation. Accordingly, we examined MIF levels in the lysates and the supernatants of L6 cell cultures that had been incubated with TNF- $\alpha$. As shown in Figure 2a, TNF- $\alpha$ treatment significantly increased the concentration of MIF in medium when compared with unstimulated control cultures. This release response was accompanied by a depletion of MIF from cell lysates, consistent with the TNF- $\alpha$-mediated secretion of MIF from preformed intracellular pools. TNF- $\alpha$ stimulation also induced a time-dependent increase in MIF mRNA levels, as measured by RT-PCR (Figure 2b).

Anti-MIF antibody inhibits TNF- $\alpha$-mediated F2,6BP production and glucose uptake in L6 cells. We next examined whether the TNF- $\alpha$-induced release of endogenous MIF from L6 cells and subsequent autocrine activation by MIF could account for the observed increase in F2,6BP production. Differentiated L6 myotubes were treated with TNF- $\alpha(1-100 \mathrm{ng} / \mathrm{ml})$, together with a neutralizing monoclonal anti-MIF antibody or isotype control antibody. As shown in Figure 3a, F2,6BP production was inhibited by as much as $70 \%$ in cells incubated with anti-MIF mAb. Cells treated with neutralizing anti-MIF mAb appeared normal morphologically, and viability testing by MTT showed no increase in cell death when compared with cells treated with an isotype control antibody (data not shown). These data strongly support the hypothesis that endogenously released, autocrine-acting MIF mediates the effect of TNF- $\alpha$ on intracellular F2,6BP levels.

TNF- $\alpha$ has been reported to increase the rate of basal glucose uptake in L6 myotubes (30, 32, 34-36); however, this effect has not been consistently observed in various muscle cell types (37-40). We next examined whether endogenous MIF, released by TNF- $\alpha$ stimulation, could mediate this action in L6 myotubes. Cells were treated with TNF- $\alpha$ (10 ng/ml for 24 hours), and the uptake of 2-deoxy-[ $\left.{ }^{3} \mathrm{H}\right]$ glucose was measured after the addition of either anti-MIF mAb or an isotype control (Figure 3b). Exposure of L6 cells to TNF- $\alpha$ in the presence of a control mAb markedly increased 2-deoxy$\left[{ }^{3} \mathrm{H}\right]$ glucose uptake under both basal conditions, and this upregulation of 2-deoxyglucose uptake was inhibited almost completely by anti-MIF mAb. The addition of anti-MIF to these cells in the absence of TNF- $\alpha$ stimulation did not affect 2 -deoxy- $\left[{ }^{3} \mathrm{H}\right]$ glucose uptake. In separate experiments, we stimulated L6 cells with insulin $(0.6 \mu \mathrm{M})$ for the final 45 minutes of incubation time in order to evaluate the contribution of MIF on insulin-stimulated glucose uptake. L6 cells are known not to upregulate expression of the hormone-sensitive GLUT4 transporter, however, and we did not observe a significant increase in 2-deoxy-[ $\left[{ }^{3} \mathrm{H}\right]$ glucose uptake over baseline in either the anti-MIF and the control antibody pretreated cells (data not shown). 


\section{Figure 2}

(a) MIF levels in L6 muscle myotube cultures. MIF was measured by ELISA in culture supernatants (solid lines) and in cell lysates (dashed lines) after treatment with $10 \mathrm{ng} / \mathrm{ml} \mathrm{TNF-} \alpha$ (filled circles) versus medium alone (open circles). There were no detectable differences in cell death as assessed by viability testing with MTT (data not shown). Data are the mean $( \pm S D)$ of three different experiments, each performed with triplicate cultures. For culture supernatants, $P<0.05$ for all TNF- $\alpha$-treated points $\geq 24$ hours versus medium alone. Error bars are absent for those points in which the width of the error bar is less than the plotted symbol. (b) Time-dependent increase in steady-state MIF mRNA levels in L6 cells after treatment with TNF- $\alpha(10 \mathrm{ng} / \mathrm{ml})$ as detected by RT-PCR.

Anti-MIF inbibits TNF- $\alpha$-mediated effects on glycolysis in vivo. We next investigated whether MIF plays a role in mediating the effects of TNF- $\alpha$ on carbohydrate metabolism in vivo. When administered to experimental animals, TNF- $\alpha$ causes an acute hypoglycemic response that is due largely to an increase in glucose uptake and enhanced glycolysis by peripheral muscle (28, 41-44). TNF- $\alpha$ administration also increases $\mathrm{F} 2,6 \mathrm{BP}$ production and lactate release from muscle and depletes liver glycogen stores (32). Utilizing a standard mouse model of TNF- $\alpha$ toxicity (42), we treated $\mathrm{BALB} / \mathrm{c}$ mice with either anti-MIF mAb or isotype control $\mathrm{mAb} 2$ hours before an intravenous injection of TNF- $\alpha$. In agreement with prior studies (45), TNF- $\alpha$ induced a significant hypoglycemia and an increase in the concentration of F2,6BP in muscle (Figure 4, $a$ and b). Pretreatment with anti-MIF mAb prevented both the TNF- $\alpha$-mediated decrease in serum glucose and significantly inhibited the increase in F2,6BP levels in muscle. The administration of TNF- $\alpha$ to mice under these experimental conditions produced a detectable increase in circulating serum MIF that was blunted by pretreatment with anti-MIF mAb (Figure 5). The greatest reduction of circulating MIF was observed at 6 a

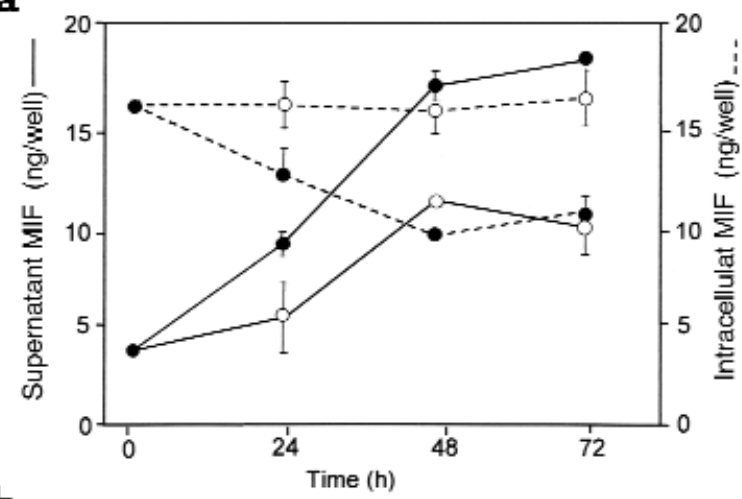

b

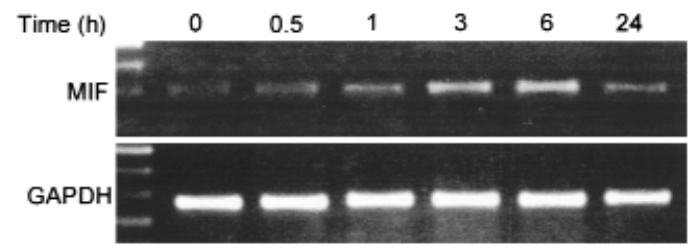

hours, which most likely reflects a peak in the plasma level and bioactivity of the intraperitoneally administered anti-MIF mAb (14).

Taken together, these data are consistent with the hypothesis that MIF mediates the enhanced glycolytic effect of TNF- $\alpha$ on skeletal muscle in vivo. MIF also is known to be expressed and released by the pancreatic $\beta$-cell, and anti-MIF mAb can inhibit glucose-stimulated insulin release from isolated pancreatic cells in vitro (19). We measured circulating insulin levels at 2 , 6 , and 12 hours after TNF- $\alpha$ treatment, and, in agreement with prior studies (37), we did not observe any detectable changes in plasma insulin concentrations (data not shown). These data suggest that the TNF$\alpha$-mediated increase in circulating MIF does not con- a

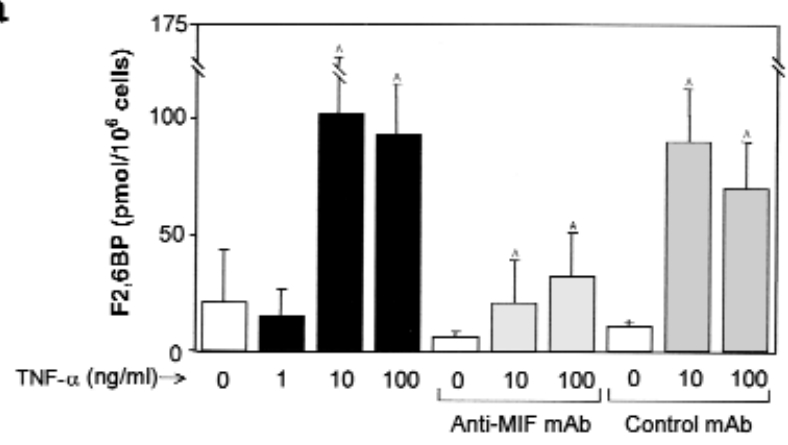

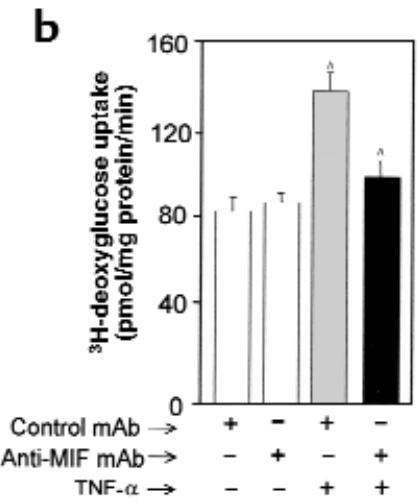

Figure 3

(a) F2,6BP levels in cultured L6 muscle cells $\left(1.4 \times 10^{6}\right.$ cells per well). Cells in triplicate wells were pretreated with medium alone, anti-MIF $\mathrm{mAb}$, or control mAb, and then stimulated with TNF- $\alpha$. After 72 hours of incubation, the cells were lysed and the intracellular F2,6BP concentrations measured as described in Methods. Data are the mean $( \pm \mathrm{SD})$ of three separate experiments. ${ }^{A} P<0.05$ versus corresponding control (TNF- $\alpha$ versus no TNF- $\alpha$, or anti-MIF versus control mAb). (b) Deoxyglucose uptake by L6 cells 24 hours after TNF- $\alpha$ (10 ng/ml) stimulation. Neither anti-MIF or control mAb $(100 \mu \mathrm{g} / \mathrm{ml})$ alone was found to alter basal or insulin-stimulated glucose uptake. Measured values were obtained in triplicate wells and are expressed as total uptake rate. The data shown (mean \pm SD) are representative of four independently performed experiments. ${ }^{A} P<0.05$ versus each corresponding control. 
tribute to hypoglycemia by promoting insulin release. Interestingly, we did observe at 2 hours a small decrease in serum insulin levels in control (non-TNF$\alpha$-treated) mice that had been treated with anti-MIF $\mathrm{mAb}$ ( 2 hours-control: $0.30 \pm 0.09 \mathrm{ng} / \mathrm{ml}$ vs. TNF- $\alpha$ : $0.46 \pm 0.13 \mathrm{ng} / \mathrm{ml}, P<0.05 ; 6$ hours-control: $0.49 \pm$ $0.18 \mathrm{ng} / \mathrm{ml}$ vs. TNF- $\alpha$ : $0.39 \pm 0.12 \mathrm{ng} / \mathrm{ml}, P=\mathrm{NS} ; 12$ hours-control: $0.23 \pm 0.08 \mathrm{ng} / \mathrm{ml}$ vs. TNF- $\alpha$ : $0.37 \pm$ $0.19 \mathrm{ng} / \mathrm{ml}, P=\mathrm{NS}$ ). This decrease in circulating
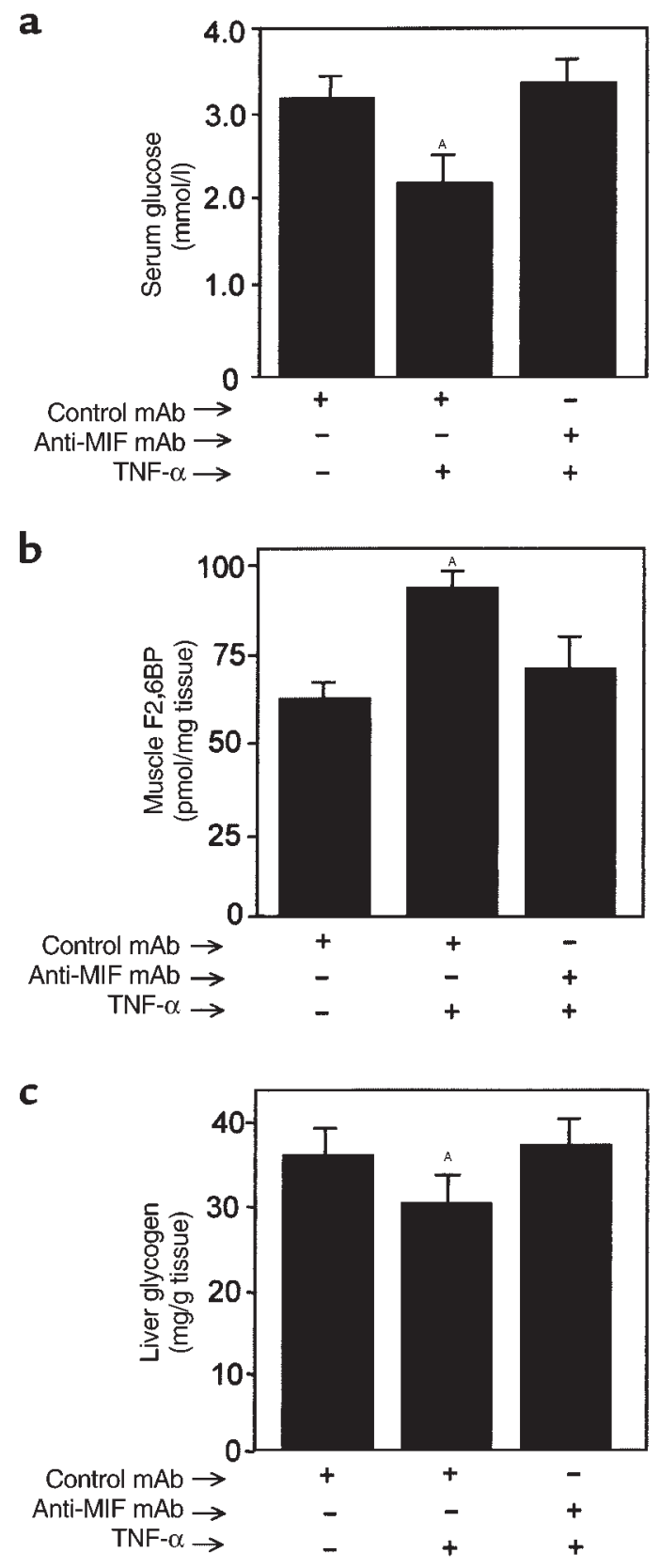

Figure 4

(a) Serum glucose, (b) muscle F2,6BP, and (c) liver glycogen levels in mice 6 hours after TNF- $\alpha$ treatment. Mice ( $n=5$ per group) were injected intraperitoneally with $100 \mu \mathrm{g}$ of anti-MIF mAb or isotype control antibody 2 hours before an intravenous injection of TNF- $\alpha$. Data are mean \pm SD and are representative of one experiment that was repeated twice. ${ }^{A} P<0.05$ versus control mAb. insulin levels is not likely to be experimentally meaningful, as these animals did not display hyperglycemia when compared with control Ab-treated mice. Nevertheless, these and prior observations (19) suggest the possibility that anti-MIF may affect the expression of insulin under certain circumstances.

Systemic TNF- $\alpha$ administration depletes hepatic glycogen stores (32), and this effect was significantly reduced in mice pretreated with anti-MIF mAb (Figure $4 c)$. The preservation of hepatic glycogen stores was found to be transient under these experimental conditions, and a significant loss of glycogen ensued after 6 hours of TNF- $\alpha$ treatment (data not shown).

Additional abnormalities that are induced acutely by TNF- $\alpha$ are an elevation in serum triglycerides, which result from an inhibition of lipoprotein lipase activity, and an increase in circulating corticosteroid levels (42, 45-47). Glucocorticoid concentrations increase in plasma as a result of a generalized stress response and act in part to counterregulate acute hypoglycemia. In our studies, TNF- $\alpha$ administration to mice increased at 2 hours both serum triglycerides (from $3.8 \pm 0.8$ to $9.2 \pm$ $5.5 \mathrm{mmol} / \mathrm{L} ; P<0.05)$, and circulating corticosterone levels (from $186 \pm 86$ to $551 \pm 70 \mathrm{ng} / \mathrm{ml} ; P<0.05$ ). No significant differences in these responses were observed in the anti-MIF versus the control antibody-treated mice, however, suggesting that MIF does not play a dominant role in these TNF- $\alpha$-mediated effects in vivo (data not shown).

To provide a more direct evaluation of the role of MIF in the catabolic effects of TNF- $\alpha$ in vivo, we performed a similar study in TNF- $\alpha-\mathrm{KO}$ mice. Injection of LPS or gram-negative bacteria induces peak expression of MIF in plasma at 6-12 hours, and the administration of anti-MIF mAb or deletion of the MIF gene has been shown recently to protect fully both wild-type and TNF- $\alpha$-deficient mice from lethal endotoxemia and gram-negative septic shock $(14,15,51)$. Anti-MIF mAb also prevented LPS-induced changes in blood glucose and muscle F2,6BP levels in a TNF- $\alpha$-deficient environment (Figure 6). These results indicate that MIF mediates these metabolic effects independently of TNF- $\alpha$. Notably, anti-MIF did not spare the depletion of liver glycogen in the TNF- $\alpha-\mathrm{KO}$ mice, suggesting that LPS-induced mediators other than TNF- $\alpha$ or MIF are sufficient for this effect.

Role of MIF in liver gluconeogenesis. An important effect of glucocorticoids is to increase the activity of PEPCK, the rate-limiting enzyme for gluconeogenesis (48). MIF counterregulates many of the anti-inflammatory effects of glucocorticoids $(12,17,22,23)$, and this prompted us to examine a potential role for MIF in the regulation of glucocorticoid-induced PEPCK activity. To test this idea, we studied the interaction of dexamethasone with MIF on PEPCK activity in the welldescribed H-4-II-E rat hepatoma cell line (49). In agreement with previous reports, the stimulation of H-4-II-E cells with dexamethasone $\left(10^{-8} \mathrm{M}\right.$ for 6 hours) produced an almost twofold increase in PEPCK activity 


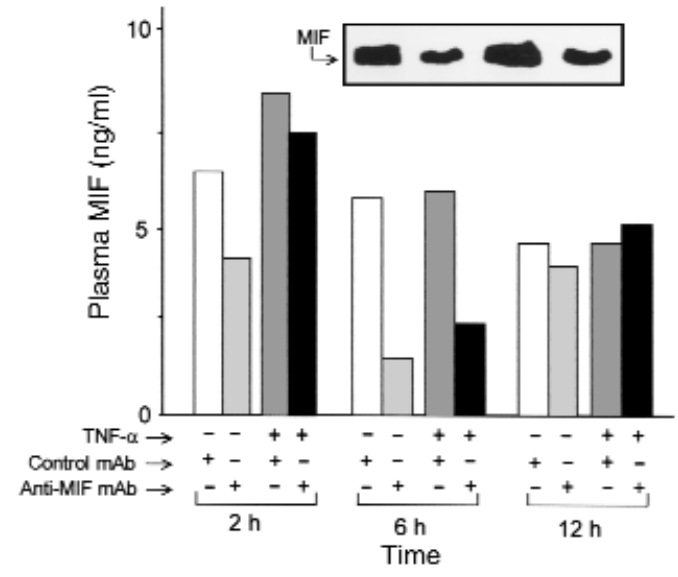

Figure 5

Plasma concentrations of MIF in mice pretreated intraperitoneally with anti-MIF or control mAb 2 hours before the intravenous injection of TNF- $\alpha$. Plasma from each animal ( $n=5$ per group) was collected at 2 , 6 , and 12 hours after TNF- $\alpha$ injection, pooled, and subjected to Western blotting analysis as described in Methods. Note that the presence of anti-MIF mAb in the serum of treated animals prevented us from quantifying these samples by sandwich ELISA. A representative Western blot result for the 6-hour time point analysis is displayed in the inset. Immunoreactive bands were quantified by laser densitometry and compared with a standard curve of $\mathrm{MIF}(1-20 \mathrm{ng})$. In a separate group of mice, we established base-line (time 0 hours) plasma MIF levels to be $2-4 \mathrm{ng} / \mathrm{ml}$, in agreement with ref. 14 .

(Figure 7). When added alone, recombinant MIF $(0.01-10.0 \mathrm{ng} / \mathrm{ml})$ showed no demonstrable effect on PEPCK activity in these cells. Notably, MIF potentiated the level of PEPCK activity induced by glucocorticoids. Although this contrasts with the counterregulatory action of MIF on glucocorticoid-mediated effects within the immune and inflammatory systems, the bell-shaped, dose-dependent response for MIF was reminiscent of its potentiating effect on cytokine production by macrophages (17).

\section{Discussion}

Microbial infection or tissue invasion can induce in the host a systemic inflammatory response that is frequently associated with increased glucose catabolism. Transient hyperglycemia and insulin resistance typically occur first, but this is followed by a persistent state of lactate production and metabolic acidosis, glycogen depletion, and hypoglycemia. In chronic infections caused by HIV, mycobacteria, and parasitic infestation, as well as in states of advanced cancer, the metabolic effects of the systemic inflammatory response frequently lead to severe tissue wasting and cachexia. These effects can contribute significantly to the overall morbidity and mortality of these conditions (1).

Inflammatory cytokines such as IL-1, TNF- $\alpha$, IL-6, and IFN- $\gamma$ have been implicated in the expression of these catabolic effects, and among these mediators, TNF- $\alpha$ has been considered to play an important, initiating role $(1,3,4,31,32)$. The effects of TNF- $\alpha$ on various parameters of cellular glucose metabolism have been investigated; however, discrepant results have been obtained both in vitro and in vivo $(3,4,30,32$, 34-36). Although TNF- $\alpha$ increases F2,6BP synthesis, glucose transport, glycogen breakdown, and lactate production in selected in vitro systems, a number of studies performed in experimental animals and in patients undergoing isolated limb perfusion have suggested that the metabolic effects of TNF- $\alpha$ may occur via the induction of a secondary mediator $(1,3,4)$.

In the present report, we provide evidence that MIF accounts for many of the previously reported effects of TNF- $\alpha$ on glucose catabolism. First, the expression of MIF mRNA and the release of MIF protein by L6 myotubes was found to be induced by TNF- $\alpha$ stimulation. Second, MIF was observed to be an autocrine/paracrine activator of the expression of PFK2. This is reminiscent of the autocrine effect of MIF on macrophage TNF- $\alpha$ production $(11,17)$, T lymphocyte IL-2 expression (12), islet insulin release (19), and fibroblast (and macrophage) MAP kinase activation (23). In myotubes, the increase in the expression level of PFK-2 was associated with an increase in the synthesis of $\mathrm{F} 2,6 \mathrm{BP}$, a powerful, positive allosteric regulator of glycolysis, and a net increase in glycolytic flux as assessed by enhanced glucose uptake and lactate release. Importantly, we found that in vivo, the administration of TNF- $\alpha$ to wild-type mice increased intracellular F2,6BP levels, decreased serum glucose levels, and depleted hepatic glycogen stores. Each of these effects was blocked by neutralization of circulating MIF with anti-MIF mAb. Anti-MIF did not spare the loss of hepatic glycogen in TNF- $\alpha-\mathrm{KO}$ mice stimulated with LPS however. This suggests that additional factors induced by proinflammatory stimulation are sufficient to mediate this effect in liver.

In addition to increasing the steady-state levels of PFK-2 mRNA, MIF is likely to exert additional regulatory effects on molecules that affect the glycolytic pathway. TNF- $\alpha$ stimulation of muscle or adipocytes has been reported in some cell types to be associated with an upregulation of glucose transport and an increase in the expression of the constitutive glucose transporter GLUT-1 $(36,50)$. We observed an inhibitory effect of anti-MIF on the TNF- $\alpha$-mediated increase in basal glucose transport of L6 myotubes. Whether this effect involves changes in the expression or activity of GLUT-1 or other transporters remains to be elucidated. Nevertheless, it is important to point out that the effect of TNF- $\alpha$ on basal glucose transport remains controversial, with contrary effects reported in cells of the same histological subtype (37-40).

In accordance with studies published previously (41), we did not observe any change in circulating insulin levels in mice treated with TNF- $\alpha$. MIF is known to be secreted by the $\beta$-cells of the pancreatic islets of Langerhans and to act in an autocrine fashion to stimulate insulin secretion (19). We did not observe any effect of anti-MIF on insulin levels in the TNF- $\alpha$-treated mice, suggesting that the normoglycemic effect of anti-MIF 
a

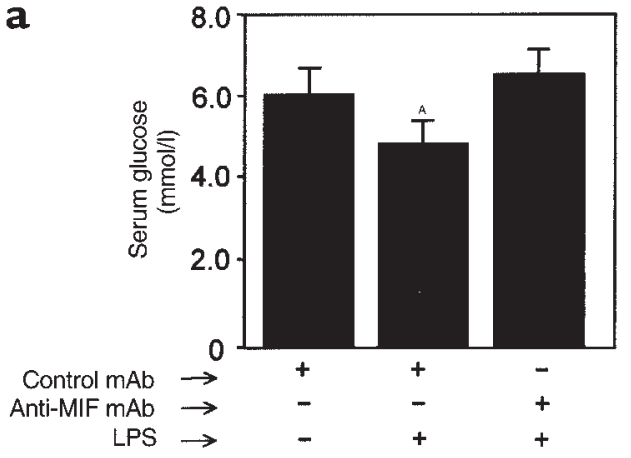

b
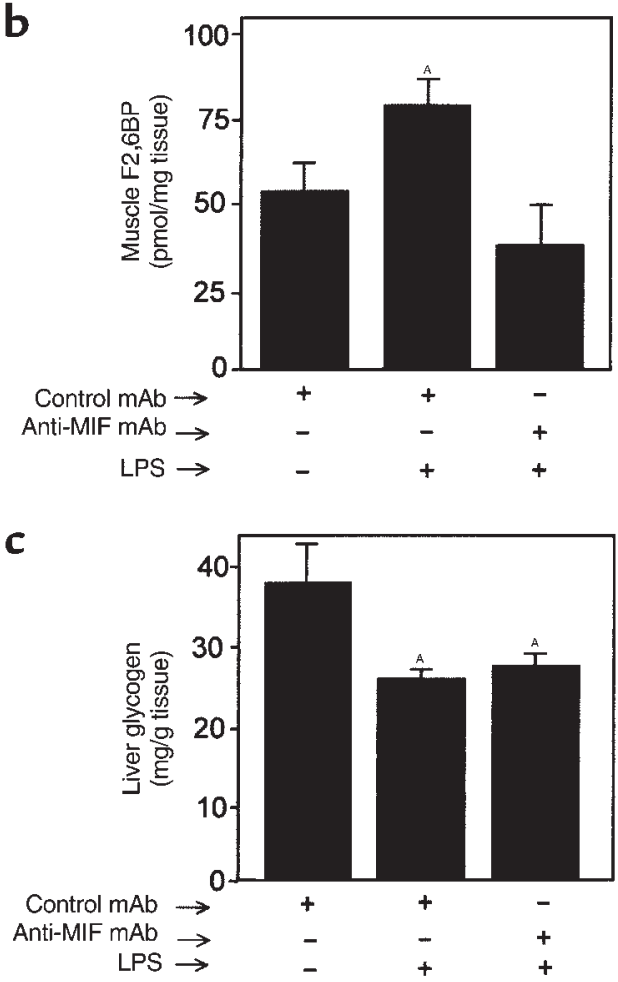

\section{Figure 6}

(a) Serum glucose, (b) muscle F2,6BP, and (c) liver glycogen levels in TNF- $\alpha-$ KO mice 8 hours after LPS treatment. Mice ( $n=5$ per group) were injected intraperitoneally with $100 \mu \mathrm{g}$ of anti-MIF mAb or isotype control antibody 2 hours before an intraperitoneal injection of $16.6 \mu \mathrm{g} \mathrm{LPS} / \mathrm{g}$ body weight. Data are expressed are mean \pm SD. ${ }^{A} P<$ 0.05 versus control mAb.

in these mice was due, in large part, to an enhancement of glucose uptake by muscle.

Circulating glucocorticoid and fatty acid levels also increase after acute TNF- $\alpha$ administration to animals $(42,46,47)$. In contrast to glucose levels, however, we did not observe any effect of anti-MIF treatment on these parameters. This suggests that under these experimental conditions, TNF- $\alpha$ affects changes in these metabolic parameters independently of MIF. Of note, high levels of circulating glucocorticoids will induce the subsequent expression of MIF in plasma (17) and in tissues (52). Anti-MIF administration thus may act to influence additional, downstream counterregulato- ry mechanisms that become expressed at later time points in the inflammatory cascade.

Recent studies have identified MIF to be a pivotal regulator of the inflammatory and immune response $(51,53)$. While first described as a T cell-derived activity, MIF has been shown to be a peptide released by pituitary cells in response to infection and stress (10). Monocytes/macrophages, $\mathrm{T}$ lymphocytes, and eosinophils also have been found to be a major source of MIF that is released after exposure to bacterial toxins $(11,13,16)$. MIF activates $T$ cells and is required for antibody production by B cells (12). Unlike any other mediator of the immune system, however, MIF release is induced by glucocorticoids and MIF has the unique ability to counterregulate the immunosuppressive effects of these steroids on macrophage cytokine production and T-cell activation $(12,17,22)$. MIF also circulates at concentrations known to exert immunoregulatory effects in vitro, lending further support to the concept that MIF and glucocorticoids function as a physiological counterregulatory dyad that controls host inflammatory and immune responses (17). Consistent with this concept, recent studies have shown that immunoneutralization of MIF or deletion of the MIF gene protected mice from lethal endotoxemia $(10,51)$, staphylococcal toxic shock $(13,51)$, or gram-negative sepsis (14) and reduced inflammation in the context of the adult respiratory distress syndrome (22), glomerulonephritis (54), and arthritis $(55,56)$.

Although evidence for a counterregulatory action for MIF in glucocorticoid-mediated suppression of inflammation and immunity has been described in several systems $(12,17,22)$, the present study has revealed one metabolic parameter: hepatic induction of PEPCK activity, in which MIF was found to have a

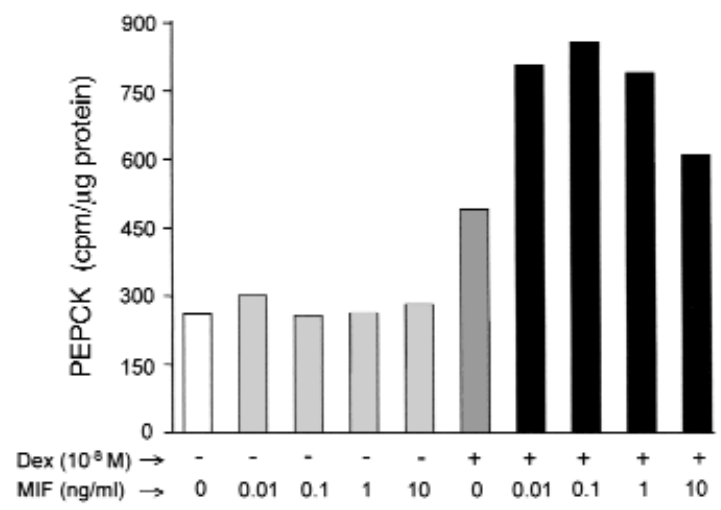

Figure 7

PEPCK activity in rat hepatocytes stimulated with MIF, dexamethasone, or MIF plus dexamethasone. Rat hepatoma $\mathrm{H}-4-\mathrm{II}-\mathrm{E}$ cells $\left(2 \times 10^{6}\right.$ cells per assay) were incubated for 6 hours with $\operatorname{rMIF}(0.1-10.0 \mathrm{ng} / \mathrm{ml})$, or dexamethasone $\left(10^{-8} \mathrm{M}\right)$ given either alone or in combination, in which case cells were preincubated for 1 hour with rMIF before the addition of dexamethasone. Cytosolic PEPCK activity was measured as described in Methods and expressed as counts per minute per microgram of cytosolic protein. Data are a mean of two separate experiments. 
potentiating role with glucocorticoids. In one respect, this potentiating effect resembled many dose studies described previously in which the MIF effect was found to be bell-shaped and with a peak effect at $0.1 \mathrm{ng} / \mathrm{ml}$ of recombinant $\operatorname{MIF}(13,17,20)$. Elucidation of the intracellular signaling pathways that mediate this effect and distinguish it from the counterregulatory interaction between MIF and glucocorticoids in immune/inflammatory cells is of paramount interest. The recent observation that MIF can induce the sustained activation of p44/p42 ERK MAP kinase may provide one avenue for exploring MIF's action in hepatocytes (23).

MIF in plasma can arise from a variety of cell sources, in addition to muscle, under the experimental conditions used in this study. Monocytes/macrophages (11), T lymphocytes (12), anterior pituitary cells (10), and the endocrine pancreas (19) may each release MIF as a consequence of systemic inflammatory stimuli. Expression studies performed either in complete (51) or tissue-specific MIF knockout mice may prove useful in elucidating the contribution of different tissues to circulating MIF under various inflammatory conditions. Moreover, such studies will be valuable in dissecting potential interactions between MIF and other cytokines expressed during the systemic inflammatory response.

Circulating MIF levels are elevated in critically ill patients with septic shock (14). The present data place MIF in a central role within host metabolic response to infection and tissue invasion, and adds to our understanding of how inflammatory pathways converge onto metabolically active tissues. Given present evidence for a pivotal role of MIF in mediating glucose disposal, hypoglycemia, and glycogen depletion in an experimental setting, it is likely that intervention in MIF action or cell signaling may alleviate the deleterious features of the hypermetabolic stress response in severely infected individuals. This would add further support to an evolving paradigm that argues for a role for anti-MIF therapy in septic shock, a concept that has arisen from data showing anti-MIF to be far less immunosuppressive than anti-TNF- $\alpha$ in severe bacterial infections $(14,57)$.

\section{Acknowledgments}

We thank Roderick E. McCallum (Texas A\&M University Health Science Center, College Station, Texas) for advice and help in measuring PEPCK activity. Kirk Manogue, Seamus Donnelly, and Günter FingerleRowson provided useful comments on the manuscript. These studies were supported by a grant (32-49129.96) and a career award (32-48916.96) from the Swiss National Science Foundation (T. Calandra), and NIH grant 1 R01 AI 42310-01 (R. Bucala).

1. Michie, H.R. 1996. Metabolism of sepsis and multiple organ failure. World J. Surg. 20:460-464.

2. Rousseau, G.G., and Hue, L. 1993. Mammalian 6-phosphofructo-2kinase/fructose-2,6-bisphosphatase: a bifunctional enzyme that controls glycolysis. Prog. Nucleic Acid Res. Mol. Biol. 45:99-127.
3. Furnsinn, C.S., et al. 1997. Acute and chronic exposure to tumor necrosis factor- $\alpha$ fails to affect insulin-stimulated glucose metabolism of isolated rat soleus muscle. Endocrinology. 138:2674-2679.

4. De Blaauw, I., et al. 1997. TNF $\alpha$ has no direct in vivo metabolic effect on human muscle. Int. J. Cancer. 71:148-154.

5. Hotamisligil, G.S., and Spiegelman, B.M. 1994. Tumor necrosis factor$\alpha$ : a key component of the obesity-diabetes link. Diabetes. 43:1271-1278.

6. Hotamisligil, G.S., Arner, P., Caro, J.F., Atkinson, R.L., and Spiegelman, B.M. 1995. Increased adipose tissue expression of tumor necrosis factor$\alpha$ in human obesity and insulin resistance. J. Clin. Invest. 95:2409-2415.

7. Bloom, B.R., and Bennett, B. 1966. Mechanism of a reaction in vitro associated with delayed-type hypersensitivity. Science. 153:80-82.

8. David, J.R. 1966. Delayed hypersensitivity in vitro: its mediation by cellfree substances formed by lymphoid cell-antigen interaction. Proc. Natl. Acad. Sci. USA. 56:72-77.

9. Weiser, W.Y., et al. 1989. Molecular cloning of a cDNA encoding human macrophage migration inhibitory factor. Proc. Natl. Acad. Sci. USA. 86:7522-7526.

10. Bernhagen, J., et al. 1993. Macrophage migration inhibitory factor (MIF) is a pituitary-derived cytokine that potentiates lethal endotoxaemia. Nature. 365:756-759.

11. Calandra, T., Bernhagen, J., Mitchell, R., and Bucala, R. 1994. The macrophage is an important and previously unrecognized source of macrophage migration inhibitory factor (MIF). J. Exp. Med. 179:1895-1902.

12. Bacher, M., et al. 1996. An essential regulatory role for macrophage migration inhibitory factor in T-cell activation. Proc. Natl. Acad. Sci. USA. 93:7849-7854.

13. Calandra, T., Spiegel, L.A., Metz, C.N., and Bucala, R. 1998. Macrophage migration inhibitory factor (MIF) is a critical mediator of the activation of immune cells by exotoxins of Gram-positive bacteria. Proc. Natl. Acad. Sci. USA. 95:11383-11388.

14. Calandra, T., et al. 2000. Protection from septic shock by neutralization of macrophage migration inhibitory factor. Nat. Med. 6:164-170.

15. Bacher, M., et al. 1997. Migration inhibitory factor (MIF) expression in experimentally induced endotoxemia. Am J. Pathol. 150:235-246.

16. Rossi, A.G., et al. 1998. Human circulating eosinophils secrete macrophage migration inhibitory factor (MIF). Potential role in asthma. J. Clin. Invest. 101:2869-2874.

17. Calandra, T., et al. 1995. MIF as a glucocorticoid-induced counter-regulator of cytokine production. Nature. 377:68-71.

18. Nishino, T., et al. 1995. Localization of macrophage migration inhibitory factor (MIF) to secretory granules within the corticotrophic and thyrotrophic cells of the pituitary gland. Mol. Med. 1:781-788.

19. Waeber, G., et al. 1997. Insulin secretion is regulated by the glucosedependent production of islet beta cell macrophage migration inhibitory factor. Proc. Natl. Acad. Sci. USA. 94:4782-4787.

20. Bernhagen, J., et al. 1994. Purification, bioactivity, and secondary structure analysis of mouse and human macrophage migration inhibitory factor (MIF). Biochemistry. 33:14144-14155.

21. Nishihira, J., et al. 1995. The structure and physicochemical properties of rat liver macrophage migration inhibitory factor. Biochim. Biophys. Acta. 1247:159-162.

22. Donnelly, S.C., et al. 1997. Regulatory role for macrophage migration inhibitory factor (MIF) in acute respiratory distress syndrome. Nat. Med. 3:320-323.

23. Mitchell, R., Metz, C.N., Peng, T., and Bucala, R. 1999. Sustained mitogen-activated protein kinase (MAPK) and cytoplasmic phospholipase A2 activation by macrophage migration inhibitory factor (MIF). J. Biol. Chem. 274:18100-18106.

24. Van Schaftingen, E., Lederer, B., Bartrons, R., and Hers, H.G. 1982. A kinetic study of pyrophosphate: fructose-6-phosphate phosphotransferase from potato tubers. Application to a microassay of fructose 2,6bisphosphate. Eur. J. Biochem. 129:191-195.

25. Bedard, S., Marcotte, B., and Marette, A. 1997. Cytokines modulate glucose transport in skeletal muscle by inducing the expression of inducible nitric oxide synthase. Biochem. J. 325:487-493.

26. Chang, H.C., and Lane, M. 1996. The enzymatic carboxylation of phosphoenolpyruvate. II. Purification and properties of liver mitochondrial phosphoenolpyruvate carboxykinase. J. Biol. Chem. 241:2413-2420.

27. McCallum, R.E., Seale, T.W., and Stith, R.D. 1983. Influence of endotoxin treatment on dexamethasone induction of hepatic phosphoenolpyruvate carboxykinase. Infect. Immun. 39:213-219.

28. Lang, C.H., Bagby, G.J., Buday, A.Z., and Spitzer, J.J. 1987. The contribution of gluconeogenesis to glycogen repletion during glucose infusion in endotoxemia. Metabolism. 36:180-187.

29. Hue, L., and Rousseau, G.G. 1993. Fructose 2,6-bisphosphate and the control of glycolysis by growth factors, tumor promoters and oncogenes. Adv. Enzyme Regul. 33:97-110.

30. Lee, M.D., Zentella, A., Vine, W., Pekala, P.H., and Cerami, A. 1987. Effect of endotoxin-induced monokines on glucose metabolism in the muscle cell line L6. Proc. Natl. Acad. Sci. USA. 84:2590-2594.

31. Chesney, J., et al. 1999. An inducible gene product for 6-phosphofructo- 
2-kinase with an AU-rich instability element: role in tumor cell glycolysis and the Warburg effect. Proc. Natl. Acad. Sci. USA. 96:3047-3052.

32. Zentella, A., Manogue, K., and Cerami, A. 1993. Cachectin/TNF $\alpha$-mediated lactate production in cultured myocytes is linked to activation of a futile substrate cycle. Cytokine. 5:436-447.

33. Jones, J.P., MacLean, P.S., and Winder, W.W. 1994. Correlation between fructose 2,6-bisphosphate and lactate production in skeletal muscle. J. Appl. Physiol. 76:2169-2176.

34. Ranganathan, S., and Davidson, M.B. 1996. Effect of tumor necrosis factor- $\alpha$ on basal and insulin-stimulated glucose transport in cultured muscle and fat cells. Metabolism. 45:1089-1094.

35. Yamasaki, H., et al. 1996. TNF- $\alpha$ stimulates glucose uptake in L6 myoblasts. Diabetes Res. Clin. Pract. 32:11-18.

36. Ciaraldi, T.P., Carter, L., Mudaliar, S., Kern, P.A., and Henry, R.R. 1998. Effects of tumor necrosis factor- $\alpha$ on glucose metabolism in cultured human muscle cells from nondiabetic and type 2 diabetic subjects. Endocrinology. 139:4793-4800.

37. Begum, N., and Ragolia, L. 1996. Effect of tumor necrosis factor-alpha on insulin action in cultured rat skeletal muscle cells. Endocrinology. 137:2441-2446.

38. del Aguila, L.F., Claffey, K.P., and Kirwan, J.P. 1999. TNF- $\alpha$ impairs insulin signaling and insulin stimulation of glucose uptake in $\mathrm{C} 2 \mathrm{C} 12$ muscle cells. Am. J. Physiol. 276:E849-E855.

39. Ling, P.R., Sierra, P., Qu, Z., and Bistrian, B.R. 1997. Insulin-like growth factor-I improves glucose utilization in tumor necrosis factor-treated rats under hyperinsulinemic-euglycemic conditions. Metabolism. 46:1052-1058.

40. Fawcett, R.L., et al. 2000. Tumor necrosis factor- $\alpha$ inhibits leptin production in subcutaneous and omental adipocytes from morbidly obese humans. J. Clin. Endocrinol. Metab. 85:530-535.

41. Metzger, S., et al. 1997. Tumor necrosis factor inhibits the transcriptional rate of glucose-6-phosphatase in vivo and in vitro. Metabolism. 46:579-583.

42. Tracey, K.J., and Cerami, A. 1993. Tumor necrosis factor: an updated review of its biology. Crit. Care. Med. 21:S415-S422.

43. Evans, D.A., Jacobs, D.O., and Wilmore, D.W. 1989. Tumor necrosis factor enhances glucose uptake by peripheral tissues. Am. J. Physiol. 257:R1182-R1189.

44. Van der Poll, T., et al. 1991. Tumor necrosis factor mimics the metabolic response to acute infection in healthy humans. Am.J. Physiol. 261:E457-E465.

45. Chajek-Shaul, T., et al. 1990. Lethal hypoglycemia and hypothermia induced by administration of low doses of tumor necrosis factor to adrenalectomized rats. Metabolism. 39:242-250.

46. Sweep, C.G., et al. 1992. Chronic intraperitoneal infusion of low doses of tumor necrosis factor- $\alpha$ in rats induces a reduction in plasma triglyceride levels. Cytokine. 4:561-567.

47. Krauss, R.M., Grunfeld, C., Doerrler, W.T., and Feingold, K.R. 1990. Tumor necrosis factor acutely increases plasma levels of very low density lipoproteins of normal size and composition. Endocrinology. 127:1016-1021.

48. Foster, D.O., Ray, P.D., and Lardy, H.A. 1966. Studies on the mechanisms underlying adaptive changes in rat liver phosphoenolpyruvate carboxykinase. Biochemistry. 5:555-562.

49. Hill, M.R., Stith, R.D., and McCallum, R.E. 1998. Human recombinant IL-1 alters glucocorticoid receptor function in Reuber hepatoma cells. $J$. Immunol. 141:1522-1528.

50. Hauner, H., Petruschke, T., Russ, M., Rohrig, K., and Eckel, J. 1995. Effects of tumour necrosis factor- $\alpha(\mathrm{TNF} \alpha)$ on glucose transport and lipid metabolism of newly-differentiated human fat cells in cell culture. Diabetologia. 38:764-771.

51. Bozza, M., et al. 1999. Targeted disruption of migration inhibitory factor gene reveals its critical role in sepsis. J. Exp. Med. 189:341-346.

52. Fingerle-Rowson, G., et al. 2000. Glucocorticoids induce the expression of macrophage migration inhibitory factor (MIF) in vivo. Cytokines and Disease Keystone Symposia. Snowbird, Utah, USA. p. 72. (Abstr.)

53. Bucala, R. 1996. MIF rediscovered: cytokine, pituitary hormone, and glucocorticoid-induced regulator of the immune response. FASEB $J$. 10:1607-1613.

54. Lan, H.Y., et al. 1997. The pathogenic role of macrophage migration inhibitory factor (MIF) in immunologically induced kidney disease in the rat. J. Exp. Med. 185:1455-1465.

55. Mikulowska, A., Metz, C.N., Bucala, R., and Holmdahl, R. 1997. Macrophage migration inhibitory factor (MIF) is involved in the pathogenesis of collagen type II-induced arthritis in mice. J. Immunol. 158:5514-5517.

56. Leech, M., et al. 1999. Macrophage migration inhibitory factor in rheumatoid arthritis. Arthritis Rheum. 42:1601-1608.

57. Martin, T.R. 2000. MIF mediation of sepsis. Nat. Med. 6:140-141. 